\title{
Erratum to: Analysis of coenzyme A activated compounds in actinomycetes
}

\author{
Matías Cabruja $^{1}$ • Bernardo Bazet Lyonnet ${ }^{1}$ - Gustavo Millán ${ }^{2} \cdot$ Hugo Gramajo ${ }^{1}$ • \\ Gabriela Gago ${ }^{1}$
}

Published online: 8 September 2016

(C) Springer-Verlag Berlin Heidelberg 2016

Erratum to: Appl Microbiol Biotechnol (2016) 100:7239-7248

DOI: $10.1007 / \mathrm{s} 00253-016-7635-0$

The original version of this article inadvertently contained mistake.

The author name Bernardo Bazet Lyonnet was incorrectly listed in the byline. See below details:

Incorrect: Lyonnet BB

Correct: Bazet Lyonnet B

The online version of the original article can be found at http://dx.doi.org/ 10.1007/s00253-016-7635-0.

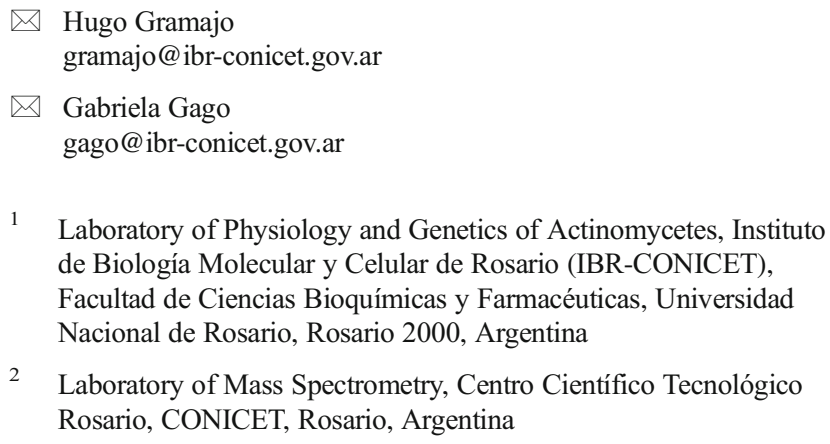

2 Laboratory of Mass Spectrometry, Centro Científico Tecnológico Rosario, CONICET, Rosario, Argentina 